PAPER

\title{
A population based epidemiological study on myasthenia gravis in Estonia
}

\author{
M Ööpik, A-E Kaasik, J Jakobsen
}

J Neurol Neurosurg Psychiatry 2003;74:1638-1643

See end of article for authors' affiliations

......................

Correspondence to: Dr Merle Ööpik, Department of Neurology Aarhus University Hospital Nørrebrogade 44, 8000 Aarhus C, Denmark; merle@akhphd.au.dk

Received 1 December 2002 In revised form 27 April 2003

Accepted 1 May 2003

\begin{abstract}
Objective: To describe the occurrence of myasthenia gravis in the Baltic area. Methods: Data were obtained from hospital files recorded during the period 1942 to 1996 from neurologists and the patient organisation. Survival data were checked with the Estonian Citizenship and Migration Board. Prevalence was determined on 1 January 1997. A questionnaire on the course of myasthenia gravis was sent to all the prevalent patients.

Results: The size of the population surveyed was 1462130 . The average annual incidence from 1970 to 1996 was 4.0 per million (women, 5.2; men, 2.6). The point prevalence was 99 per million (women, 133; men 59). The incidence in the younger age group ( $<50$ years) was 3.4 per million (women, $4.8 ;$ men, 1.9) and in the older age group ( $\geqslant 50$ years), 5.5 (women, $5.9 ;$ men, 4.9 ). The prevalence ratio was twofold higher in the older age group $(p<0.0001)$ - for men $(p=0.034)$ as well as for women $(p<0.001)$. Conclusions: Prevalence and incidence values of myasthenia gravis from Estonia are similar to those reported in most studies from Europe and north America. However, there seems to be a higher frequency in the elderly ( $\geqslant 50$ years) in Estonia.
\end{abstract}

$\mathrm{T}$ here are only a few studies on the epidemiology of myasthenia gravis based on complete populations. ${ }^{1-4}$ There is also a paucity of information on the occurrence of myasthenia gravis in eastern Europe, though recently, regional studies were published from part of Croatia and from Belgrade, Yugoslavia. ${ }^{5}$ Estonia was a part of the former Soviet Union during the period 1940 to 1991. A thorough search of published reports on the occurrence of myasthenia gravis in the former Soviet Union revealed only one study, from the Krasnodar territory in south Russia on the Black Sea. ${ }^{7}$ There have been no studies on myasthenia gravis in the Baltic countries. We now report epidemiological and clinical data of the first east European, population based study on myasthenia gravis, carried out in Estonia in the Baltic region.

\section{METHODS}

\section{Study area}

Estonia $\left(45227 \mathrm{~km}^{2}\right)$ is situated in the northeastern part of Europe, on the southern coast of the Gulf of Finland. On I January 1997 the population of Estonia was 1462130 inhabitants (781 416 women and 680714 men). ${ }^{8}$

Estonia has a relatively long tradition of qualified and available neurological services. There were 153 neurologists ( 1.0 per 10000 inhabitants) at the end of 1996. All patients with suspected neurological diseases are seen by a neurologist, either following self-referral or after referral by general practitioners or other specialists. Patients with suspected neuromuscular disorders are referred for a final diagnosis to the department of neurology, Tartu University Hospital, serving as a diagnostic centre for south Estonia, or to the department of neurology, Hospital of Neurology and Psychiatry, Tallinn, for north Estonia. Tartu University Hospital is the only university hospital in Estonia and serves as the national competence centre for complicated cases.

\section{Case finding methods}

All patients included had an established diagnosis of myasthenia gravis. The diagnostic criteria were: muscle weakness and rapid fatigue aggravated by exercise and relieved by rest in one or more muscle groups; and a positive response to anticholinergic drugs.

The data on discharged patients with myasthenia gravis were obtained from the files recorded during the period 1 January 1942 to 31 December 1996 at the department of neurology, Tartu University Hospital and the department of neurology, Hospital of Neurology and Psychiatry, Tallinn. The other departments of neurology, practising neurologists, and the Estonian Association for Patients with Muscular Disorders were contacted to find other patients with the disease who had not been admitted to the two centres.

Since 1942 complete data on admission and discharge of patients have been preserved in the archives of the department of neurology, Tartu University Hospital, including the case histories since 1945. The data from the department of neurology, Hospital of Neurology and Psychiatry, Tallinn have been available since its establishment in 1955. A computer database with a diagnostic index was established at the Tartu University Hospital in 1978. The International Classification of Diseases (ICD), eighth revision, with the code for myasthenia gravis (733.0) was used to retrieve records of the Tartu University Hospital from the period 1978 to 1985 , and the ICD, ninth revision, with the code for myasthenia gravis (358.0), to retrieve the records from 1986 to 1996. Earlier records and the records from the Department of Neurology, Hospital of Neurology and Psychiatry, Tallinn, were retrieved manually.

The medical records were examined according to the diagnostic criteria by one of us (MÖ). In case of doubt the diagnosis was discussed with the other authors. Twenty six patients with a diagnosis of myasthenic syndrome, myasthenic-myopathic syndrome, and pseudomyasthenia were excluded.

We selected 1 January 1997 as a prevalence day. Survival data were checked by the Estonian Citizenship and Migration Board. Complete population data are available in the Statistical Office of Estonia since 1970. Thus incidence rates for the period 1970 to 1996 were calculated, including cases diagnosed in Estonia or abroad in residents of Estonia. 
A questionnaire about the onset and course of the disease, comorbidity, and treatment was sent to all the prevalent patients a maximum of three times.

\section{Statistical analysis}

All incidence rates and prevalence ratios were calculated per one million inhabitants. The $95 \%$ confidence intervals (95\% CI) were calculated from the Poisson distribution. ${ }^{9}$ Incidence rates and prevalence ratios were age and sex adjusted by the direct method to the European and world standard populations for cross national comparisons. ${ }^{10}$

For group comparison, the Mann-Whitney U test, the $\chi^{2}$ test, and Fischer's exact test were used. Probability $(p)$ values of $<0.05$ were considered significant. Statistical analysis was done with the STATISTICA program.

\section{RESULTS}

During the period 1 January 1942 to 31 December 1996, the diagnosis of myasthenia gravis was established in 208 patients (148 women and 60 men). Figure 1 shows the case identification from the various sources of information. Two hundred and two patients were inhabitants of Estonia at the time of diagnosis. In six patients, myasthenia gravis was diagnosed before immigration to Estonia.

\section{Incidence}

During the period I January 1970 to 31 December 1996, myasthenia gravis was diagnosed in 162 patients (113 women, 49 men). The total crude incidence was 4.0 (95\% CI, 3.4 to 4.7 ) per million per year. After adjustment by age to the European standard population, the incidence was still 4.0 (3.4 to 4.7), while adjustment to the world standard population gave a rate of 3.7 (3.2 to 4.3$)$. The crude incidence was higher for women $(5.2(4.3$ to 6.3$))$ than for men $(2.6$ (1.9 to 3.4$))(|z|=4.13, \mathrm{p}<0.001)$.

The age and sex specific incidence rates are shown in table 1 . In most age specific groups the rates for women were higher than for men. The difference was approximately fourfold in the age groups 20 to 29 years $(|z| 2.78, \mathrm{p}=<0.01)$ and 30 to 39 years $(|z|=2.81, \mathrm{p}=<0.01)$.

The female to male ratio in the younger age group $(<50$ years) was 2.5 to 1 , and in the older ( $\geqslant 50$ years), 2.0 to 1 . The incidence in the younger age group was 3.4 (2.7 to 4.1$)$ per million (women, 4.8 (3.8 to 6.1); men, 1.9 ( 1.3 to 2.8$)$ ) and in the older age group, 5.5 (4.2 to 7.0) (women, 5.9 (4.3 to 7.9); men, 4.9 (3.0 to 7.5$))$. In $60.5 \%$ of the patients myasthenia gravis was diagnosed before the age of 50 years.
Figure 2 shows the annual incidence rates from 1970 to 1996. The average annual incidence increased as follows: 1970 to 1978: 1.4 (95\% CI 0.8 to 2.2 ); 1979 to $1987: 4.8$ (3.7 to $6.1) ; 1988$ to $1996: 5.7$ (4.5 to 7.1$)$. There was a significant increase in the incidence in the period 1979 to 1987 compared with the period 1970 to $1978(|z|=4.88, \mathrm{p}<0.001)$. The increase was significant for women $(|z|=4.28, \mathrm{p}<0.001)$ as well as for men $(|z|=2.38, \mathrm{p}<0.05)$. Comparison of the periods 1988 to 1996 and 1979 to 1987 showed an increased incidence in men only $(|z|=2.13, \mathrm{p}<0.05)$.

\section{Prevalence}

On 1 January 1997, there were 144 patients (104 women, 40 men) with a diagnosis of myasthenia gravis in Estonia (fig 1). The female to male ratio was 2.6 to 1 . The median age for both sexes was 49.5 years (range 4.1 to 82.4 ) - 44.0 years (range 4.1 to 76.8 ) for men and 50.1 years (range 7.8 to 82.4 ) for women.

The prevalence ratio on l January 1997 was 99 (95\% CI 83 to 116) per million. After adjustment by age to the European standard population the ratio was 96 (81 to 113 ), and after adjustment to the world standard population, 82 (70 to 97). The prevalence ratio was higher for women (133 (109 to 162)) than for men $(59$ (42 to 80)) $(|z|=4.52, \mathrm{p}<0.001)$.

Age and sex specific prevalence ratios are shown in table 2. In all age specific groups the ratios for women were higher than for men. The difference was approximately fourfold in age groups 40 to $49(|z|=3.01, \mathrm{p}<0.01)$ and 50 to 59 $(|z|=3.01, p<0.01)$. In older age group $(\geqslant 50$ years $)$ the prevalence ratio was twofold higher $(|z|=4.50, \mathrm{p}<0.0001)$ than in the younger age group ( $<50$ years), both for men $(|z|=2.12, \mathrm{p}=0.034)$ and for women $(|z|=3.37, \mathrm{p}<0.001)$.

The prevalence ratio in south Estonia (146 (110 to 190)) was higher than in north Estonia (82 (65 to 101)) $(|z|=3.42, p<0.001)$. In south Estonia the prevalence ratio was higher both for women $(|z|=2.75, \mathrm{p}<0.01)$ and men $(|z|=2.06, \mathrm{p}<0.05)$.

\section{Clinical data}

One hundred and eighteen patients (82\%; 30 men, 88 women) responded to the questionnaire, while 26 failed to reply to three requests. The median age for responders was 50.7 years (range 4.1 to 82.4 ): 50.9 years (range 4.1 to 76.8 ) for men and 50.7 years (range 7.8 to 82.4 ) for women. The median age for non-responders was lower: 38.5 years (range 17.0 to 74.8$)$ for the whole group $(n=26) ; 33.0$ years (range 17.0 to 71.5$)$ for men $(n=10)$; and 43.1 years (range 22.4 to 74.8.) for women $(n=16)$. However, the difference was not

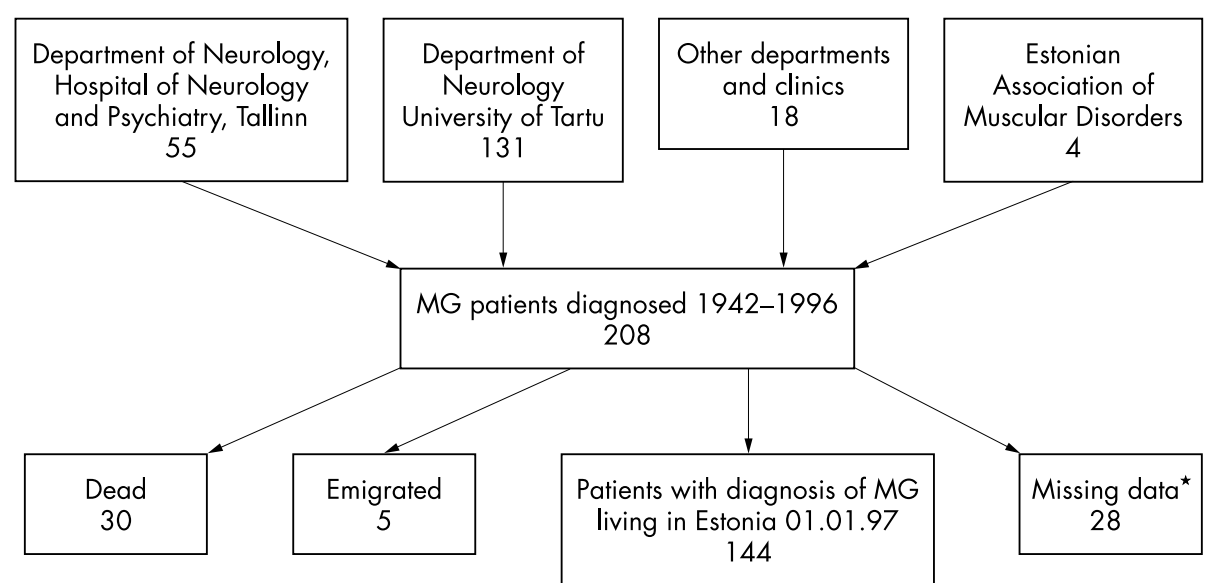

Figure 1 Case identification. *Missing data represent the cases not registered by the Estonian Citizenship and Migration Board on 1 January 1997. 
Table 1 Age and sex specific annual incidence rates (per million) of myasthenia gravis in Estonia during the period 1970 to 1996

\begin{tabular}{|c|c|c|c|c|c|c|c|c|c|c|}
\hline \multirow{2}{*}{$\begin{array}{l}\text { Age } \\
\text { group } \\
\text { (years) }\end{array}$} & \multicolumn{3}{|c|}{ Mean annual population 1983} & \multicolumn{3}{|c|}{ Cases of myasthenia gravis } & \multicolumn{3}{|c|}{ Incidence rates $(95 \% \mathrm{Cl})$} & \multirow[b]{2}{*}{ p Values* } \\
\hline & Men & Women & Total & Men & Women & Total & Men & Women & Total & \\
\hline $0-9$ & 114396 & 109472 & 223868 & 4 & 2 & 6 & $1.3(0.3$ to 3.3$)$ & $0.7(0.1$ to 2.49$)$ & $1.0(0.4$ to 2.2$)$ & 0.4472 \\
\hline 10-19 & 108410 & 100849 & 209259 & 8 & 16 & 24 & $2.7(1.2$ to 5.4$)$ & 5.9 (3.4 to 9.5$)$ & $4.2(2.7$ to 6.3$)$ & 0.0702 \\
\hline 20-29 & 118253 & 115044 & 233297 & 5 & 18 & 23 & $1.6(0.5$ to 3.6$)$ & 5.8 (3.4 to 9.2$)$ & 3.7 (2.3 to 5.5$)$ & 0.00544 \\
\hline $30-39$ & 102469 & 105421 & 207890 & 6 & 21 & 27 & $2.2(0.8$ to 4.7$)$ & 7.4 (4.6 to 11.3 ) & $4.8(3.2$ to 7.0$)$ & 0.00496 \\
\hline $40-49$ & 97321 & 106258 & 203579 & 5 & 13 & 18 & $1.9(0.6$ to 4.4$)$ & 4.5 (2.4 to 7.7$)$ & $3.3(1.9$ to 5.2$)$ & 0.0892 \\
\hline $50-59$ & 82189 & 107251 & 189440 & 8 & 17 & 25 & $3.6(1.6$ to 7.1$)$ & $5.9(3.4$ to 9.4$)$ & 4.9 (3.2 to 7.2$)$ & 0.2502 \\
\hline $60-69$ & 41067 & 72715 & 113782 & 5 & 19 & 24 & 4.5 (1.5 to 10.5$)$ & $9.7(5.8$ to 15.1$)$ & $7.8(5.0$ to 11.6$)$ & 0.1188 \\
\hline 70-79 & 28287 & 63939 & 92226 & 8 & 7 & 15 & 10.5 (4.5 to 20.6$)$ & $4.1(1.6$ to 8.4$)$ & 6.0 (3.4 to 9.9$)$ & 0.0574 \\
\hline $80-89$ & 7827 & 27097 & 34924 & 0 & 0 & 0 & $0.0(0.0$ to 14.2$)$ & $0.0(0.0$ to 4.1$)$ & $0.0(0.0$ to 3.2$)$ & \\
\hline Total & 700219 & 808046 & 1508265 & 49 & 113 & 162 & $2.6(1.9$ to 3.4$)$ & $5.2(4.3$ to 6.3$)$ & $4.0(3.4$ to 4.7$)$ & $<0.001$ \\
\hline \multirow{2}{*}{\multicolumn{7}{|c|}{$\begin{array}{l}\text { Adjusted to the European standard population } \\
\text { Adjusted to the world standard population }\end{array}$}} & $2.8(2.0$ to 3.6$)$ & $5.2(4.3$ to 6.3$)$ & $4.0(3.4$ to 4.7$)$ & $<0.001$ \\
\hline & & & & & & & 2.5 (1.8 to 3.3$)$ & $4.9(4.0$ to 5.9$)$ & 3.7 (3.2 to 4.3$)$ & $<0.001$ \\
\hline
\end{tabular}

*Statistical differences between the rates in men $v$ women.

statistically significant (total $(|z|=1.71, \mathrm{p}=0.087)$; men $(|z|=1.22, \mathrm{p}=0.223)$; women $(|z|=0.82, \mathrm{p}=0.412)]$. A $\chi^{2}$ test showed no difference in sex between the groups $\left(\chi^{2}=1.8, \mathrm{df}=1, \mathrm{p}=0.179\right)$.
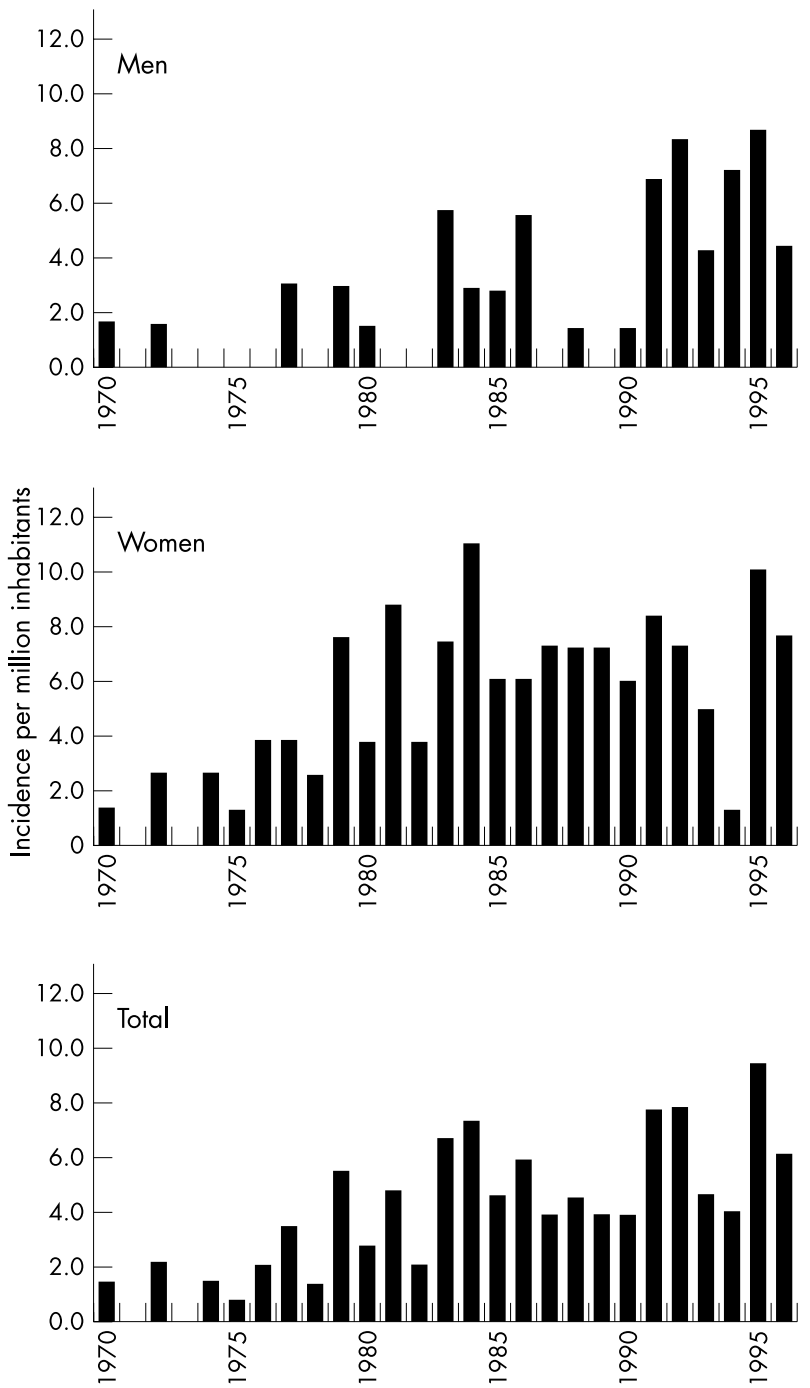

Figure 2 Annual incidence of myasthenia gravis in Estonia during the period 1970 to 1996. Values are per million inhabitants.
More specific clinical data about age at onset, onset symptoms, age of the patient at first visit to the doctor for specific myasthenic symptoms, and age at diagnosis were available in 108 patients ( 81 women, 27 men). The median age for the whole group was 49.9 years (range 7.8 to 82.4 ): 49.2 years (range 10.7 to 76.8 ) for men and 50.2 years (range 7.8 to 82.4 ) for women. The median age for the group of patients with incomplete data and for non-responders $(\mathrm{n}=36)$ was 43.1 years (range 4.1 to 74.8$)$ : 35.7 years (range 4.1 to 71.5$)$ for men $(n=13)$, and 50.1 years (range 16.0 to 74.8 for women $(\mathrm{n}=23)$. There was no significant difference in age (total $(|z|=1.15, \mathrm{p}=0.251)$; men $(|z|=1.03$, $\mathrm{p}=0.305)$; women $(|z|=0.40, \mathrm{p}=0.687))$ or $\operatorname{sex}\left(\chi^{2}=1.7\right.$, $\mathrm{df}=1, \mathrm{p}=0.197)$ between the groups.

The median age at onset of the disease was 34.0 years (range 6.4 to 70.5 ). The median age at first visit to a doctor for myasthenic symptoms was 35.0 years (range 6.7 to 70.5 ), and the median age at diagnosis was 35.3 years (range 7.0 to 73.0). Myasthenia gravis was diagnosed within three months in 34 patients $(32 \%)$, within one year in $71(66 \%)$, within two years in $84(78 \%)$, and within three years in $93(86 \%)$. Figure 3 shows the delay in diagnosis. The median period from onset of disease to first visit to the doctor was 1.0 month (range one day to 23 years) and from first visit to the doctor to establishment of the diagnosis, 3.1 months. The median period from onset of disease to diagnosis was 6.1 months. There were no differences between men and women.

Initially, 43 patients $(40 \%)$ consulted a general practitioner, $36(33 \%)$ a neurologist, $23(21 \%)$ an ophthalmologist, and four another specialist. Five patients could not provide information about referral.

Ocular symptoms were present in 64 patients $(59 \%)$ at disease onset. In 30 patients $(28 \%)$ the only presenting symptom was weakness of ocular muscles; in seven patients $(6 \%)$ it was weakness of bulbar muscles; and in 21 patients $(19 \%)$ it was weakness of girdle and extremity muscles. Generalised weakness was present in 40 patients (37\%) and difficulty in breathing in $10(9 \%)$ at the onset.

Myasthenia gravis was diagnosed by the primary physician in eight patients and was the suspected diagnosis in an additional seven. Disorders of eye muscles or nerves were diagnosed in seven patients. The suspected disorders included generalised muscle disorders (3), multiple sclerosis (2), brain tumour (2), brain infarction or transitory ischaemia of the brain (3), psychiatric disorders (6), tiredness (3), and others. In 24 cases no diagnosis was made at the first consultation.

Thyroid disorders were diagnosed in six patients with myasthenia gravis and rheumatoid arthritis in 10. 
Table 2 Age and sex specific prevalence ratios (per million) of myasthenia gravis in Estonia on 1 January 1997

\begin{tabular}{|c|c|c|c|c|c|c|c|c|c|c|}
\hline \multirow{2}{*}{$\begin{array}{l}\text { Age } \\
\text { group } \\
\text { (years) }\end{array}$} & \multicolumn{3}{|c|}{ Population on 1 January 1997} & \multicolumn{3}{|c|}{$\begin{array}{l}\text { Cases of myasthenia } \\
\text { gravis }\end{array}$} & \multicolumn{3}{|l|}{ Prevalence ratio $(95 \% \mathrm{Cl})$} & \multirow[b]{2}{*}{ p Value* } \\
\hline & Men & Women & Total & Men & Women & Total & Men & Women & Total & \\
\hline $0-9$ & 91501 & 87155 & 178656 & 1 & 1 & 2 & $10.9(0.3$ to 60.9$)$ & $11.5(0.3$ to 63.9$)$ & $11.2(1.4$ to 40.4$)$ & 0.976 \\
\hline $10-19$ & 109132 & 105674 & 214806 & 5 & 5 & 10 & 45.8 (14.8 to 106.8$)$ & 47.3 (15.3 to 110.3 ) & 46.6 ( 22.3 to 85.7$)$ & 0.9602 \\
\hline 20-29 & 107330 & 101067 & 208397 & 5 & 12 & 17 & $46.6(15.1$ to 108.6$)$ & 118.7 (61.4 to 207.8$)$ & 81.6 (47.5 to 130.5 ) & 0.0688 \\
\hline $30-39$ & 103187 & 105520 & 208707 & 7 & 9 & 16 & 67.8 (27.2 to 139.8$)$ & 85.3 (39.1 to 162.1 ) & 76.7 (43.8 to 124.2 ) & 0.6456 \\
\hline $40-49$ & 96649 & 107129 & 203778 & 6 & 24 & 30 & 62.1 (22.8 to 135.3$)$ & 224.0 (143.6 to 333.8$)$ & $147.2(99.4$ to 210.5$)$ & $<0.01$ \\
\hline $50-59$ & 75021 & 92816 & 167837 & 4 & 22 & 26 & $53.3(14.6$ to 136.5$)$ & 237.0 (148.6 to 272.6 ) & $154.9(101.2$ to 227.7$)$ & $<0.01$ \\
\hline $60-69$ & 62309 & 91383 & 153692 & 5 & 22 & 27 & $80.2(26.0$ to 187.0$)$ & 240.7 (150.9 to 363.5$)$ & 175.7 (1 15.8 to 254.7$)$ & 0.0198 \\
\hline 70-79 & 26198 & 60931 & 87129 & 7 & 8 & 15 & $267.2(107.1$ to 550.4$)$ & 131.3 (15.6 to 258.7$)$ & $172.2(96.4$ to 284.1$)$ & 0.1616 \\
\hline $80-89$ & 9387 & 29741 & 39128 & 0 & 1 & 1 & $0.0(0.0$ to 319.6$)$ & $33.6(0.9$ to 187.3$)$ & $25.6(0.6$ to 142.4$)$ & 0.5754 \\
\hline Total & 680714 & 781416 & 1462130 & 40 & 104 & 144 & $58.8(42.0$ to 79.9$)$ & $133.1(109.3$ to 162.0$)$ & 98.5 (83.3 to 116.3 ) & $<0.001$ \\
\hline \multirow{2}{*}{\multicolumn{7}{|c|}{$\begin{array}{l}\text { Adjusted to the European standard population } \\
\text { Adjusted to the world standard population }\end{array}$}} & $60.3(43.0$ to 82.0$)$ & $128.0(105.1$ to 155.8$)$ & $96.0(81.2$ to 113.4$)$ & $<0.001$ \\
\hline & & & & & & & 52.1 (37.2 to 70.9$)$ & $109.6(73.9$ to 133.4$)$ & $82.4(69.7$ to 97.3$)$ & $<0.001$ \\
\hline
\end{tabular}

In two cases, a mother and her daughter, the disease was familial.

\section{DISCUSSION}

The reliability of epidemiological studies depends on complete case identification. ${ }^{11}$ The case finding method used in this study should allow identification of most patients in Estonia with a diagnosis of myasthenia gravis. It is likely, however, that there are a few patients with a mild undiagnosed disorder who are relatively free of symptoms.

As expected, a majority of patients $(69 \%)$ were diagnosed at Tartu University Hospital. The four patients diagnosed in outpatient clinics were recognised by practising neurologists.

The average annual incidence in our study is comparable with most other reports ${ }^{12412-16}$ and is also in accordance with Kurtzke's estimation that incidence of myasthenia gravis is between two and six per million. ${ }^{17}$ Some of the later studies have observed rates between 7.1 and 11.1 per million. ${ }^{6}{ }^{18-21}$ The highest average annual incidences reported so far are 15 per million in Cyprus ${ }^{22}$ and 14.7 in Italy. The latter report is the only prospective study hitherto available. ${ }^{23}$

Owing to the rarity of the disease only a few population studies $^{413} 17$ contain a sufficient number of patients for reliable estimation of age and sex specific incidence rates. ${ }^{14}$ The pattern of age and sex specific incidences found in this study is similar to most other reports ${ }^{4142123}$ and supports

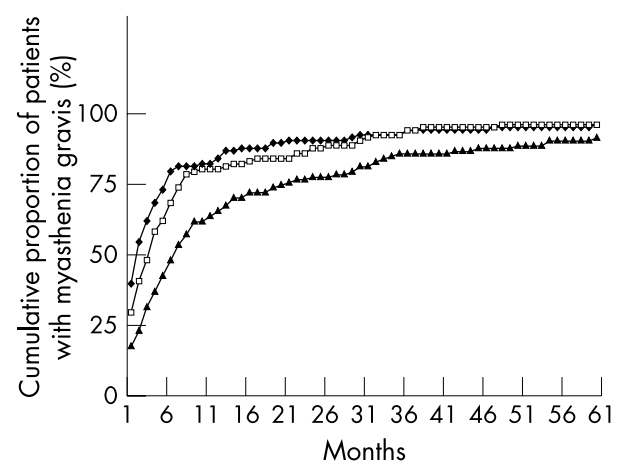

Figure 3 Delay in diagnosis. The median period from onset of disease to first visit to the doctor was 1.0 months, from first visit to the doctor to establishment of the diagnosis, 3.1 months, and from onset of disease to diagnosis, 6.1 months. Black diamonds, period from onset of the disease to first visit to the doctor; white squares, period from first visit to the doctor to establishment of the diagnosis; black triangles, period from onset of the disease to diagnosis. the hypothesis that younger women are more susceptible to myasthenia gravis than younger men, whereas in the elderly there appear to be no important sex differences. ${ }^{13} 1423$

An increase in annual incidence from 0.2 to 2.0 per million population was reported in Norway during 10 year periods from 1912 to 1951. During the subsequent three decades the incidence stabilised at around 4.0 per million. ${ }^{4}$ In eastern Denmark the annual incidences per million varied at random around a mean value of 4.4 during 1970 to 1987, whereas in western Denmark they increased from 3.0 to 6.6 during the three five year periods between 1975 and 1989. ${ }^{13}{ }^{14}$ Possibly owing to better case identification and an increased proportion of elderly patients, an increased incidence was observed in western Virginia, USA ${ }^{1824}$ and in Cambridgeshire, England. ${ }^{21}$ The increase in incidence in our study during the period 1979 to 1987 may reflect improved neurological services in Estonia after 1970. The increased incidence in men during the period 1988 to 1996 could be explained by application of improved neurophysiological techniques at Tartu University Hospital at a time when myasthenia gravis was considered to be predominantly a disorder of women. ${ }^{17}$

The prevalence ratio of myasthenia gravis in Estonia is comparable to those in countries around the Baltic sea. ${ }^{3412-14} 2025$ Kurtzke estimated the likely prevalence of myasthenia gravis to be about 40 per million population, ${ }^{16}$ but recent studies report more than threefold higher ratios. ${ }^{6}{ }^{18} 21$ The highest prevalence ratio reported so far is 175 per million..$^{22}$ The prevalence ratios in various countries have been compared on the basis of reported ratios. ${ }^{12} 13161721$ In this paper, we have adjusted the prevalence ratios of some of the major studies by the world and the European standard populations (table 3).

Most investigators have found a predominance of women among prevalent patients, ranging from 1.5 to 2.6 when comparing absolute figures. ${ }^{13412131521}$ One study reported an equal female to male ratio. ${ }^{22}$ The relatively high female to male ratio in our study (2.6:1) could be explained by the higher proportion of women in the Estonian population, especially among the elderly. In 1995 the mean life expectancy at birth was 67.9 years in Estonia, being 61.7 years for men and 74.3 years for women. ${ }^{8}$

Higher incidences and prevalence ratios in the older age group could be the result of improved diagnosis and treatment during recent years. ${ }^{14} 18192426$ This suggests that myasthenia gravis is predominantly a disorder of elderly people, and the number of patients with the disease will increase as the population ages. ${ }^{18}$

Some investigators have found a higher prevalence of myasthenia gravis in areas with higher population densities, ${ }^{1613}$ better availability of neurological services, 
Table 3 Prevalence ratios of myasthenia gravis (per million) in various countries

\begin{tabular}{|c|c|c|c|c|c|c|}
\hline & \multicolumn{2}{|l|}{ Men } & \multicolumn{2}{|l|}{ Women } & \multicolumn{2}{|l|}{ Total } \\
\hline & Observed & Adjusted* & Observed & Adjusted* & Observed & Adjusted* \\
\hline Estonia & 58.8 & $60.3(52.1)$ & 133.1 & $128.0(109.6)$ & 98.5 & 96.0 (82.4) \\
\hline Norway ${ }^{4}$ & 51.6 & $60.7(48.2)$ & 122.4 & $137.1(118.1)$ & 122.4 & $99.2(83.1)$ \\
\hline Denmark $^{13}$ & 53.2 & $50.4(39.1)$ & 101.6 & $95.4(80.6)$ & 77.5 & $72.5(59.4)$ \\
\hline England $^{21}$ & 96.8 & $98.3(64.9)$ & 195.2 & 183.4 (142.9) & 146.2 & $138.2(102.2)$ \\
\hline Yugoslavia ${ }^{6}$ & 98.8 & 74.2 & 142.5 & 111.1 & 121.5 & 95.6 \\
\hline Virginia $^{18}$ & 82.0 & $112.6(90.4)$ & 285.0 & 167.7 (153.2) & 135.8 & $140.3(122.0)$ \\
\hline
\end{tabular}

and a longer tradition of epidemiological surveys. ${ }^{1} 420$ Consequently, population, territory size, different behaviour of the patients in various areas, and different power of information sources may bias prevalence studies on the disease. $^{127}$ We observed a higher prevalence ratio in south Estonia. In comparison with other countries there is a relatively large number of neurologists in Estonia, but there is no difference in the relative number of neurologists in the north and the south, neither were there any differences in age and sex. The population density is $38.9 / \mathrm{km}^{2}$ in north Estonia and $24.2 / \mathrm{km}^{2}$ in south Estonia. The north-south gradient of the prevalence ratio might indicate differences in case finding in the two regions but might equally reflect regional differences in disease occurrence. In addition, epidemiological studies of rare diseases in smaller populations will lead to increased variation in estimates, emphasising the importance of studies involving entire populations.

The median age at onset has been reported to be in the range of 31 to 40 years. ${ }^{6}{ }^{16}$ Our results are in accordance with this estimate, but do not support the observation that women have a younger median age at onset than men. ${ }^{24}$

It has been reported that patients are most often referred by general practitioners to a neurologist. ${ }^{28}$ During the study period, however, the patients had the possibility of referring themselves to specialists in Estonia. It is of interest that approximately one third of the patients themselves initially suspected a neurological disorder.

The delay from the onset of myasthenia gravis to the first visit to the doctor, and the delay from this visit to the final diagnosis, have not been analysed previously. Our results show that most of the patients consulted a physician soon after the onset of symptoms. However, the total diagnostic delay in our study was comparable with that of other studies. ${ }^{15} 16202328$ We could not confirm the finding that a diagnosis was made at an earlier stage in men than in women. ${ }^{28}$

Our observation of a wide variety of preliminary diagnoses and the diagnostic delay support the view that myasthenia gravis is a difficult disease to diagnose. ${ }^{2021}$ As expected, ${ }^{6}{ }^{12} 14-162123$ the most common presenting symptom was weakness of the ocular muscles. The frequency of familial cases in our study was comparable with previous reports. ${ }^{6}{ }^{30}$ The most common associated conditions were thyroid diseases and rheumatoid disorders, but thyroid diseases were diagnosed less often in the present study than in previous reports. $^{615252930}$

\section{Conclusions}

These data from the first population based study of myasthenia gravis in the Baltic region suggest that this is predominantely a disorder of the elderly, and that younger women are more susceptible than younger men. Prevalence and incidence values from Estonia are similar to those reported in most studies from Europe and north America.

\section{ACKNOWLEDGEMENTS}

We gratefully acknowledge the Estonian Association of Muscular Disorders and Muskelsvindfonden, Denmark. The study was supported by grant No 1869 from the Estonian Science Foundation and by grants from Tartu and Aarhus Universities.

\section{Authors' affiliations}

M Ööpik, J Jakobsen, Department of Neurology, Aarhus University Hospital, Aarhus, Denmark

A-E Kaasik, Department of Neurology, Tartu University Hospital Tartu, Estonia

Competing interests: none declared

\section{REFERENCES}

1 Hokkanen E. Epidemiology of myasthenia gravis in Finland. J Neurol Sci 1969:9:463-78.

2 Gudmundsson KR. The prevalence of some neurological diseases in Iceland. Acta Neurol Scand 1968:44:57-69.

3 Pirskanen R. Genetic aspects in myasthenia gravis. A familial study of 264 Finnish patients. Acta Neurol Scand 1977;56(6):365-88.

4 Storm-Mathisen A. The epidemiology of myasthenia gravis in Norway. Acta Neurol Scand 1984:70:274-84.

5 Zivadinov R, Jurjevic A, Willheim K, et al. Incidence and prevalence of myasthenia gravis in the county of the coast and Gorski kotar, Croatia, 1976 through 1996. Neuroepidemiology 1998;17:265-72.

6 Lavrnic D, Jarebinski M, Rakocevic-Stojanovic V, et al. Epidemiological and clinical characteristics of myasthenia gravis in Belgrade, Yugoslavia (19831992). Acta Neurol Scand 1999;100:168-74

7 Krivopusk ME. Kliniko-epidemiologicheskie aspekty nasledstvennykh nervnomyshechnykh zabolevanii v Krasnodarskom Krae. Zh Nevropatol Psikhiatr Im S S Korsakova 1991;91:3-5. [In Russian.]

8 Statistical Office of Estonia. Statistical yearbook of Estonia. Tallinn, Estonia: The Office, 1997:42-55.

9 Schoenberg BS. Calculating confidence intervals for rates and ratios. Simplified method utilizing tabular values based on the Poisson distribution. Neuroepidemiology 1983;2:257-65.

10 Waterhouse J, Muir C, Correa P, et al. eds. Cancer incidence in five continents, vol 3 (IARC Scientific Publications No 15). Lyon: International Agency for research on Cancer, 1976:456.

11 Kurland LT. Descriptive epidemiology of selected neurologic and myopathic disorders with particular reference to a survey in Rochester, Minnesota. $J$ Chron Dis 1958;8:378-418.

12 Oosterhuis HJGH. The natural course of myasthenia gravis: a long-term follow-up study. J Neurol Neurosurg Psychiatry 1989:52:1121-7.

13 Somnier FE, Keiding N, Paulson OB. Epidemiology of myasthenia gravis in Denmark. A longitudinal and comprehensive population survey. Arch Neurology 1991;48:733-9.

14 Christensen PB, Jensen TS, Tsiropulous I, et al. Incidence and prevalence of myasthenia gravis in western Denmark: 1975 to 1989. Neurology 1993;43:1779-83.

15 Yu YL, Hawkins BR, Ip MSM, et al. Myasthenia gravis in Hong Kong Chinese. 1. Epidemiology and adult disease. Acta Neurol Scand 1992;86:113-19.

16 Holtsema H, Mourik J, Rico RE, et al. Myasthenia gravis on the Duch antilles: an epidemiological study. Clin Neurol Neurosurg 2000;102:195-8.

17 Kurtzke JF. Epidemiology of myasthenia gravis. Adv Neurol 1978:19:545-64.

18 Phillips LH, Torner JC, Anderson MS, et al. The epidemiology of myasthenia gravis in central and western Virginia. Neurology 1992;42:1888-93.

19 Schon F, Drayson M, Thompson RA. Myasthenia gravis and elderly people. Age Ageing 1996;25:56-8.

20 Sørensen TT, Holm E-B. Myasthenia gravis in the county of Viborg, Denmark. Eur Neurol 1989:29:177-9.

21 Robertson NP, Deans J, Compston DA. Myasthenia gravis: a population based epidemiological study in Cambridgeshire, England. J Neurol Neurosurg Psychiatry 1998:65:492-6.

22 Kyriallis K, Hristova AH, Middleton LT. What is the real epidemiology of myasthenia gravis? [Abstract.] Neurology 1995;45(suppl 4):A351-2. 
23 Emilia-Romagna Study Group. Incidence of myasthenia gravis in the EmiliaRomagna region: a prospective study. Neurology 1998;51:255-8.

24 Phillips LH, Torner JC. Epidemiologic evidence for a changing natural history of myasthenia gravis. Neurology 1996:47:1233-8.

25 Thorlacius S, Aarli JA, Riise T, et al. Associated disorders in myasthenia gravis: autoimmune diseases and their relation to thymectomy. Acta Neurol Scand 1989;80:290-5.

26 Aarli JA. Late-onset myasthenia gravis: a changing scene. Arch Neurol 1999:56:25-7.
27 D'Alessandro R, Granieri E, Benassi G, et al. Comparative study on the prevalence of myasthenia gravis in the provinces of Bologna and Ferrara, Italy. Acta Neurol Scand 1991;83:83-8.

28 Beekman R, Kuks JB, Oosterhuis HJ. Myasthenia gravis: diagnosis and followup of 100 consecutive patients. J Neurol 1997:244:112-18.

29 Donaldson DH, Ansher M, Horan S, et al. The relationship of age to outcome in myasthenia gravis. Neurology 1990;40:786-90.

30 Christensen PB, Jensen TS, Tsiropoulos I, et al. Associated autoimmune diseases in myasthenia gravis. Acta Neurol Scand 1995:91:192-5.

\section{NEUROLOGICAL PICTURE}

\section{Ulcus terebrans: an unusual cause of paraparesis}

A rare case of progressive paraplegia is described. A 55 year old man was admitted on 18 February 2002, because of gradually increasing weakness in both legs, sensory disturbance below the level of $\mathrm{T} 7$, and a significant loss of body weight.

A physical examination revealed an oval giant ulcerating tumour of the back, measuring $30 \mathrm{~cm} \times 20 \mathrm{~cm}$, which destroyed the skin of the entire thoracic area, the subcutaneous tissue, and the thoracolumbar fascia, and invaded the muscles. The spinous processes of the T5-T8 thoracic vertebrae were exposed centrally (fig 1). The lesion has been growing over a 10 year period and finally developed into an ulcus terebrans. The patient had not received any previous treatment because of his attitude of neglect.

MRI of the spine showed an advanced ulcerating tumour, which had deeply destroyed larger parts of the back, infiltrating the thoracic spine at T5-8 vertebral level (fig 2A). Axial Tl-weighted MRI of the T7 vertebrae demonstrated a tumour mass that extended into the spinal canal, compressed the cord, and involved the vertebral body (fig 2B). The lesion was biopsied and histopathologically diagnosed as an ulcerating basal cell carcinoma. Tumour nests with peripheral palisading invaded deeply into the subcutaneous tissue and were accompanied by vascular invasion. The man refused complete surgical removal. He received palliative irradiation and he was alive at last follow up.

Basal cell carcinoma, the most common skin cancer, is locally invasive but rarely metastasises. ${ }^{1}$ Only $10 \%$ of all basal cell carcinomas are located on the trunk.

Small basal cell carcinomas of the trunk are usually regarded as relatively harmless. In contrast, large and ulcerating basal cell carcinomas may become a therapeutic

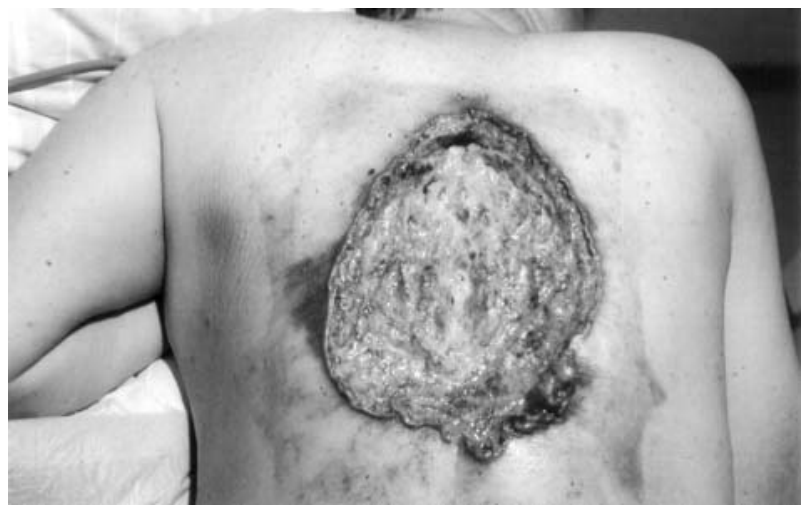

Figure 1 An advanced ulcus terebrans of the back due to neglect.

challenge with a less favourable prognosis and high risk of recurrence. ${ }^{2}$ The development of mutilating giant basal cell carcinomas appears less due to the biological aggressive character of the tumours, but rather to the patients' attitude of neglect. ${ }^{2}$

T Birbilis

ZKH Sankt-Jürgen-Strasse, Neurochirurgische Klinik, Sankt-Jürgen-Strasse 1, D-28205 Bremen, Germany; betheod@aol.com

\section{References}

1 Malone JP, Fedok FG, Belchis DA, et al. Basal cell carcinoma metastatic to the parotid: report of a new case and review of the literature. Ear Nose Throat $J$ 2000;79(7):511-5.

2 Berking C, Konz B, Pfutzner W, et al. Basalioma terebrans of trunk skin. A neglected tumor. Hautarzt 1998;49(9):719-21.
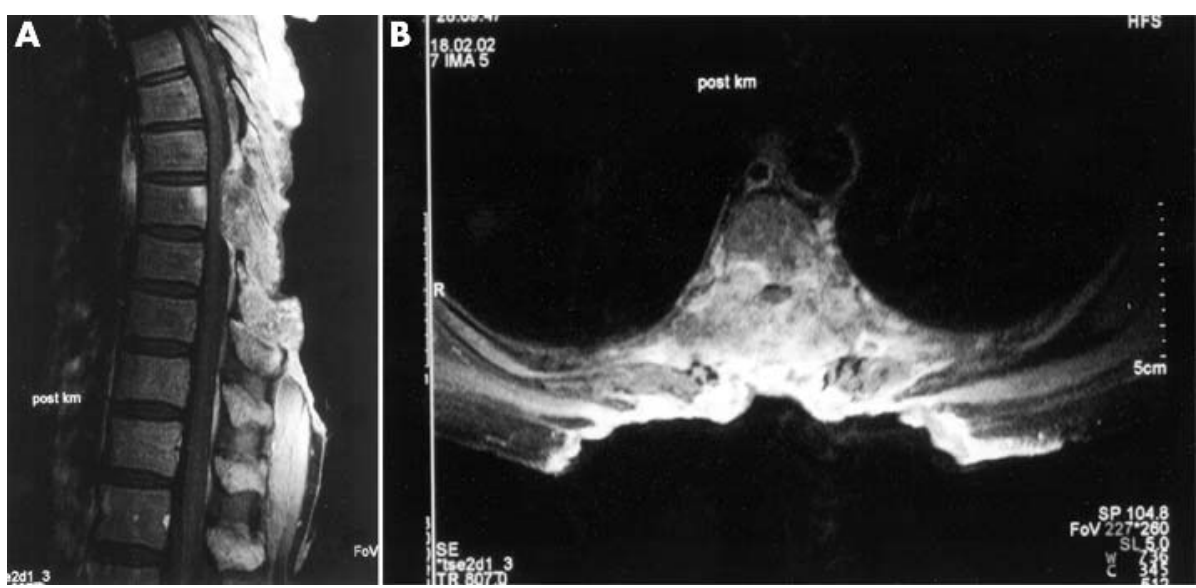

Figure 2 Spine MRI findings. 